\title{
Effects of glucocorticoids combined with probiotics in treating Crohn's disease on inflammatory factors and intestinal microflora
}

\author{
HUI SU, QIAN KANG, HAIHONG WANG, HUI YIN, LINGHUI DUAN, YULI LIU and RUYING FAN \\ Department of Gastroenterology, PLA Army General Hospital, Beijing 100700, P.R. China
}

Received March 13, 2018; Accepted June 12, 2018

DOI: $10.3892 /$ etm.2018.6559

\begin{abstract}
This study investigated the effect of glucocorticoids combined with probiotics on inflammatory factors and intestinal microflora in the treatment of Crohn's disease. Eighty-three patients with Crohn's disease were selected from March 2015 to December 2017 in PLA Army General Hospital (Beijing, China). A total of 83 patients were randomly divided into the control group and treatment group. Patients in the control group were treated with routine treatment of oral sulfasalazine. Besides oral sulfasalazine, patients in the treatment group were treated with probiotics combined with glucocorticoids. At the same time, a total of 40 healthy individuals were selected to serve as the healthy group (received no treatment). Clinical efficacy, changes of inflammatory factors, incidence of infection and changes of intestinal flora were compared between the different groups. After treatment, the levels of inflammatory factors in both groups significantly decreased, and the reduction in the treatment group significantly increased than that in the control group $(\mathrm{P}<0.05)$. The levels of inflammatory cytokines in the treatment group reached the levels of that in the healthy individuals after treatment. After treatment, the levels of yeast, enterococci and peptococcus of the two groups of patients were significantly decreased, while the level of lactobacillus was significantly increased, and the changes were more significant in the treatment group than those in the control group. After treatment, the number of intestinal flora in the treatment group reached that of the healthy individuals. Treatment efficiency of the treatment group was significantly higher than that of the control group, and the infection rate of the control group was significantly higher than that of the treatment group $(\mathrm{P}<0.05)$. The use of probiotics combined with glucocorticoid in the treatment of Crohn's disease can improve clinical curative effect, reduce the secretion of inflammatory factors and improve the level of intestinal flora, so as to achieve better outcomes compared with conventional method.
\end{abstract}

Correspondence to: Dr Ruying Fan, Department of Gastroenterology, PLA Army General Hospital, 5 Nanmencang, Beijing 100700, P.R. China

E-mail: scorpio81@sina.com

Key words: Crohn's disease, probiotics, glucocorticoid, intestinal flora

\section{Introduction}

Crohn's disease is a chronic gastrointestinal disease mainly related to eating habits and autoimmune function, and clinical statistical analysis found that the incidence of this disease in China is increasing (1-3). Crohn's disease can cause systemic symptoms, such as lesions in mouth, eyes, skin, and gastrointestinal tract. Occurrence site of Crohn's disease is mainly the gastrointestinal tract, and highest incidence is found in ileum and colon $(4,5)$. Clinically, Crohn's disease is mainly treated with antibiotics, immunosuppressive agents and other drugs (6-9). Antibiotics may cause the development of intestinal flora resistance, and the immunosuppressive agents are not affordable for most patients. At present, probiotics and glucocorticoid are incresingly widely used to treat this disease $(2,10,11)$. In this study, probiotics combined with glucocorticoid therapy was used to treat Crohn's disease. The clinical treatment effects were observed and compared.

\section{Patients and methods}

Materials. A total of 83 patients with Crohn's disease were selected from March 2015 to December 2017 in PLA Army General Hospital (Beijing, China). Patients were randomly divided into the control group and treatment group. The treatment group included 23 males and 20 females, with an average age of $43.43 \pm 5.43$ years and an average disease duration of $2.12 \pm 1.09$ years. The control group included 20 males and 20 females, with an average age of $48.43 \pm 5.43$ years and an average disease duration of $2.01 \pm 1.02$ years. The healthy group included 19 males and 21 females, with an average age of $44.76 \pm 4.99$ years. There was no significant difference between the three groups in general information such as age, sex and disease duration.

Inclusion criteria were: patients who met the criteria for 'diagnosis and treatment of inflammatory bowel disease'; patients who were not suffering from heart, liver or other vital organ injuries; patients without mental diseases; patients who could cooperate with the researchers.

Exclusion criteria were: patients who were allergic to probiotics and glucocorticoids; patients who were pregnant or in lactation; patients with other intestinal diseases.

The study was approved by the Ethics Committee of PLA Army General Hospital (Beijing, China). Patients who participated in this study, signed an informed consent and had complete clinical data. Signed informed consents were obtained from the patients or guardians. 
Table I. Comparison of general clinical data between two groups of patients (n).

\begin{tabular}{|c|c|c|c|c|c|c|c|c|c|}
\hline \multirow[b]{2}{*}{ Groups } & \multirow[b]{2}{*}{ Cases } & \multicolumn{2}{|c|}{ Sex } & \multicolumn{3}{|c|}{ Lesion localization } & \multicolumn{3}{|c|}{ Lesion type } \\
\hline & & Male & Female & Ilecolon & Ileum & Colon & Stenosis & Penetration type & Non-penetration type \\
\hline Treatment & 43 & 23 & 20 & 19 & 17 & 7 & 21 & 15 & 7 \\
\hline Control & 40 & 20 & 20 & 15 & 16 & 9 & 19 & 14 & 7 \\
\hline
\end{tabular}

Table II. Comparison of inflammatory cytokines between two groups of patients (mean $\pm \mathrm{SD})$.

\begin{tabular}{|c|c|c|c|c|}
\hline Groups & Time-points & CRP (ng/ml) & TNF- $\alpha(\mathrm{ng} / \mathrm{ml})$ & IL-10 (pg/ml) \\
\hline \multirow[t]{3}{*}{ Treatment } & Before treatment & $13.39 \pm 0.93$ & $2.45 \pm 0.21$ & $14.35 \pm 1.67$ \\
\hline & After treatment & $7.21 \pm 0.89$ & $0.72 \pm 0.08$ & $10.23 \pm 1.86$ \\
\hline & P value & $<0.001$ & $<0.001$ & $<0.001$ \\
\hline \multirow[t]{4}{*}{ Control } & Before treatment & $13.51 \pm 1.21$ & $2.61 \pm 0.21$ & $14.98 \pm 1.45$ \\
\hline & After treatment & $10.56 \pm 1.09$ & $1.72 \pm 0.11$ & $13.25 \pm 1.75$ \\
\hline & $\mathrm{P}$ value $\mathrm{e}^{\mathrm{b}}$ & $<0.001$ & $<0.001$ & $<0.001$ \\
\hline & $\mathrm{P}_{\text {value }}{ }^{\mathrm{C}}$ & $<0.001$ & $<0.001$ & $<0.001$ \\
\hline \multirow[t]{2}{*}{ Healthy individuals } & & $6.23 \pm 0.65$ & $0.69 \pm 0.08$ & $9.81 \pm 0.99$ \\
\hline & $P$ value ${ }^{d}$ & $<0.001$ & $<0.001$ & $<0.001$ \\
\hline
\end{tabular}

${ }^{\mathrm{a} C}$ Comparison between before and after treatment in the treatment group; ${ }^{\mathrm{b}} \mathrm{Comparison}$ between before and after treatment in the control group; ${ }^{\mathrm{c}}$ Comparison between after treatment in the control group and after treatment in the treatment group; ${ }^{\mathrm{d}}$ Comparison between the healthy group and after treatment in the treatment group.

Table III. Comparison of intestinal flora between two groups of patients and healthy individuals (mean \pm SD).

\begin{tabular}{|c|c|c|c|c|c|}
\hline Groups & Time-points & Yeast & Enterococci & Lactobacilli & Peptococcus \\
\hline Treatment & $\begin{array}{c}\text { Before treatment } \\
\text { After treatment }\end{array}$ & $\begin{array}{l}2.23 \pm 0.21 \\
1.03 \pm 0.01^{\mathrm{a}}\end{array}$ & $\begin{array}{l}6.73 \pm 0.65 \\
5.32 \pm 0.43^{\mathrm{a}}\end{array}$ & $\begin{array}{l}5.63 \pm 0.53 \\
8.31 \pm 0.82^{\mathrm{a}}\end{array}$ & $\begin{array}{l}6.23 \pm 0.63 \\
3.89 \pm 0.32^{\mathrm{a}}\end{array}$ \\
\hline Control & $\begin{array}{c}\text { Before treatment } \\
\text { After treatment }\end{array}$ & $\begin{array}{l}2.42 \pm 0.21 \\
1.59 \pm 0.12^{\mathrm{a}, \mathrm{b}}\end{array}$ & $\begin{array}{l}6.79 \pm 0.62 \\
6.21 \pm 0.60^{\mathrm{a}, \mathrm{b}}\end{array}$ & $\begin{array}{l}5.73 \pm 0.51 \\
6.93 \pm 0.62^{\mathrm{a}, \mathrm{b}}\end{array}$ & $\begin{array}{l}6.29 \pm 0.61 \\
5.79 \pm 0.59^{\mathrm{a}, \mathrm{b}}\end{array}$ \\
\hline Healthy individuals & & $0.92 \pm 0.08$ & $5.24 \pm 0.52$ & $8.23 \pm 0.80$ & $3.93 \pm 0.34$ \\
\hline
\end{tabular}

${ }^{\mathrm{a}} \mathrm{P}<0.05$, compared with the pretreatment level; ${ }^{\mathrm{b}} \mathrm{P}<0.05$, compared with the treatment group.

Table IV. Comparison of clinical efficacy of two groups of patients (n).

\begin{tabular}{|c|c|c|c|c|c|c|}
\hline Groups & Cases & Recovery & $\begin{array}{l}\text { Markedly } \\
\text { effective }\end{array}$ & Effective & Ineffective & $\begin{array}{c}\text { Total effective } \\
\text { rate }(\%)\end{array}$ \\
\hline Treatment & 43 & 15 & 21 & 6 & 1 & 42 (97.6) \\
\hline Control & 40 & 8 & 15 & 11 & 6 & $34(85.3)^{\mathrm{a}}$ \\
\hline
\end{tabular}

${ }^{\mathrm{a}} \mathrm{P}<0.05$, compared with the treatment group.

Methods. Patients in the control group were treated with routine treatment of oral sulfasalazine at a dose of $1 \mathrm{~g}$ each time, 4 times per day. Besides oral sulfasalazine, patients in the treatment group were treated with probiotics combined with glucocorticoids. Probiotics: Bifidobacterium Lactobacillus triple tablets, at the dose of 4 x $500 \mathrm{mg}$ per time, 2 times per day. Glucocorticoids: prednisone, at the initial dose of $0.75-1.0 \mathrm{mg} / \mathrm{kg} /$ day and gradually stopped in 3-4 months. 
Table V. Comparison of incidence of infection between two groups of patients (n).

\begin{tabular}{lcccccc}
\hline Groups & Cases & $\begin{array}{c}\text { Infectious abdominal } \\
\text { distension and diarrhea }\end{array}$ & Abdominal abscess & Pulmonary infection & Sepsis & Incidence (\%) \\
\hline Treatment & 43 & 8 & 9 & 4 & 1 & $22(51.1)$ \\
Control & 40 & 12 & 11 & 8 & 5 & $36(92.7)^{\mathrm{a}}$ \\
\hline
\end{tabular}

${ }^{\mathrm{a}} \mathrm{P}<0.05$, compared with the treatment group.

Efficacy evaluation and observation indicators. The levels of inflammatory cytokines C-reactive protein (CRP, TNF- $\alpha$ and IL-10) were measured before and after treatment. The inflammatory cytokines were determined by using ELISA kit (Beyotime, Shanghai, China).

Determination of intestinal flora: fresh feces was collected from patients and healthy individuals, and yeast, peptococcus, lactobacilli and enterococci were isolated, cultured and detected.

Clinical efficacy: recovery, clinical symptoms and signs disappeared after treatment, stool routine examination was negative, microscopic ulcer was healed, mucosal recovery was observed; markedly effective, clinical symptoms and signs disappeared after treatment, stool routine examination was negative, microscopic ulcer was mostly healed; effective, clinical symptoms and signs disappeared after treatment, stool routine examination was negative and mild inflammation was observed by microscopic examination; ineffective, clinical symptoms and signs were not improved or aggregated. Total effective rate $=$ (recovered cases + apparent effective cases + effective cases)/total number $\times 100 \%$.

Statistical analysis. Statistical software SPSS 17.0 (SPSS Inc., Chicago, IL, USA) was used to analyze the data. Enumeration data were expressed as mean \pm standard deviation. Enumeration data were recorded as a number. Comparison between multiple groups was done using One-way ANOVA test followed by a post hoc test (Least Significant Difference). $\mathrm{P}<0.05$ was considered to indicate a statistically significant difference.

\section{Results}

Comparison of general clinical data between the two groups of patients. There were 23 males and 20 females in the treatment group, including 19 patients with ileocolic, 17 patients with ileum, 7 patients with colon, and 21 patients with stenosis and 15 patients with penetration type and 7 patients with non-penetration type. There were 20 males and 20 females in the control group, including 15 patients with ileocolic, 16 patients with ileum, 9 patients with colon, and 19 patients with stenosis and 14 patients with penetration type and 7 patients with non-penetration type. There was no significant difference in sex, lesion location and type of lesion between the two groups (Table I).

Comparison of inflammatory cytokines between the two groups of patients. Before treatment, the levels of CRP, TNF- $\alpha$ and IL-10 in the treatment group were $13.39 \pm 0.93 \mathrm{ng} / \mathrm{ml}$,
$2.45 \pm 0.21 \mathrm{ng} / \mathrm{ml}$ and $14.35 \pm 1.67 \mathrm{pg} / \mathrm{ml}$, respectively. No significant differences in the levels of CRP, TNF- $\alpha$ and IL-10 were found between the two groups. After treatment, the levels of these inflammatory factors in both groups were significantly decreased, and the levels of the inflammatory factors in the treatment group were significantly lower than those in the control group $(\mathrm{P}<0.05)$. The levels of the inflammatory factors in the treatment group reached the levels of that in the control group (Table II).

Comparison of intestinal flora between the groups of patients and healthy individuals. Before treatment, no significant differences in number of yeast, enterococci, lactobacilli and peptococcus intestinal flora were found between the two groups. After treatment, the levels of yeast, enterococci and peptococcus of the groups of patients were significantly decreased, while the level of lactobacillus was significantly increased in both groups, and the changes were more significant in the treatment group than those in the control group. After treatment, the number of intestinal flora in the treatment group reached that of the healthy individuals (Table III).

Comparison of clinical efficacy of the two groups of patients. In the treatment group, 15 patients recovered, 21 were marke dly effective, 6 were effective, and the total effective rate was $97.6 \%$. In the control group, 8 patients recovered, 15 were markedly effective, and 11 patients were effective, and the total effective rate was $85.3 \%$. Therapeutic efficiency of the the treatment group was significantly higher than that of the control group $(\mathrm{P}<0.05)$ (Table IV).

Comparison of incidence of infection between the two groups of patients. In the treatment group, 8 patients developed infectious abdominal distension and diarrhea, 9 patients developed abdominal abscess, 4 patients developed pulmonary infection, 1 patient developed sepsis, and the overall incidence was $51.1 \%$. In the control group, 12 patients developed infectious abdominal distension and diarrhea, 11 patients developed abdominal abscess, 8 patients developed pulmonary infection, 5 patients developed sepsis, and the overall incidence was $92.7 \%$. The infection rate of the control group was significantly higher than that of the treatment group $(\mathrm{P}<0.05)($ Table $\mathrm{V})$.

\section{Discussion}

Crohn's disease is an inflammatory bowel disease that can cause serious complications of infection. Antibiotics are generally used in the treatment of Crohn's disease, while long-term 
use of antibiotics may lead to the development of resistance, which in turn may affect treatment outcomes $(12,13)$. In this study, probiotics combined with glucocorticoid was used to treat Crohn's disease, so as to explore the clinical efficacy of this treatment effect and the impact on intestinal flora.

Treatment with probiotics is safe for the intestine, and can provide nutrients for the intestine, improve the level of intestinal flora and maintain the balance of flora $(14,15)$. Glucocorticoids can rapidly diffuse into the cytoplasm after entering the body and bind to hormone receptors in cells. Glucocorticoid can bind to corresponding reactants and activate the expression of relevant genes to exert anti-inflammatory effects $(16,17)$.

TNF- $\alpha$ as the major inflammatory and immune function factor in the body is mainly produced by activated monocytes and megakaryocytes. When inflammation occurs, the level of TNF- $\alpha$ significantly increases, thereby inducing the secretion of a variety of inflammatory factors and adhesion molecules. IL-10 as an important inflammatory factor in Crohn's disease is mainly produced by activated monocytes. IL-10 inhibits the secretion of inflammatory mediators by monocytes, and has a strong anti-inflammatory effect. In Crohn's disease, intestinal flora is imbalanced mainly due to the proliferation of yeast. At the same time, the numbers of enterococcus and peptococcus were significantly increased, while the number of lactobacillus was decreased, seriously affecting the intestinal digestive function $(18,19)$.

This study showed that the effective rate of the treatment group was significantly higher than that of the control group (97.6 vs. $85.3 \%$ ), indicating the use of probiotics combined with glucocorticoid treatment can improve treatment effect and effectively alleviate clinical symptoms. After treatment, the levels of inflammatory factors in the treatment group were significantly lower than those in the control group. After entering the human body, probiotics can improve intestinal damage, protect intestinal wall permeability, thereby reducing the levels of proinflammatory substances such as inflammatory cytokines and endotoxin in lamina propria, thereby inhibiting inflammation. Glucocorticoids reduce the secretion of arachidonic acid, which is a proinflammatory precursor in the body, thereby inhibiting the production and secretion of inflammatory cytokines. After treatment, intestinal flora was improved, the levels of yeast, enterococci and peptococcus were significantly decreased, and the level of lactobacillus was increased. The improvement is more significant in the treatment group than that in the control group, indicating the probiotics combined with glucocorticoid treatment can play a better role than conventional methods in protecting intestinal flora. Results also showed that probiotics combined with glucocorticoid treatment can reduce the incidence of infection, abdominal distension, diarrhea and other side effects.

In conclusion, the use of probiotics combined with glucocorticoid in the treatment of Crohn's disease can improve clinical efficacy, reduce infection rate, improve the protective effect of intestinal flora, and effectively control the production and secretion of inflammatory cytokines. Therefore, this treatment should be popularized in clinical practice.

\section{Acknowledgements}

Not applicable.

\section{Funding}

This study was supported by National Science and Technology Support Program (2014BAI09B05) and The Special Fund of Capital Health Research and Development (starting fund no. 2018-1-5091).

\section{Availability of data and materials}

The datasets used and/or analyzed during the present study are available from the corresponding author on reasonable request.

\section{Authors' contributions}

HS, QK and RF conceived and designed the experiments, and performed the statistical analysis. HS, QK and HW performed most of the experiments. HS contributed to the writing of the manuscript. QK and HW helped to draft the manuscript. HY, LD and YL contributed to the acquisition of data. All the authors have read and approved the final version of this study.

\section{Ethics approval and consent to participate}

The study was approved by the Ethics Committee of PLA Army General Hospital (Beijing, China). Patients who participated in this study, signed an informed consent and had complete clinical data. Signed informed consents were obtained from the patients or guardians.

\section{Patient consent for publication}

Not applicable.

\section{Competing interests}

The authors declare that they have no competing interests.

\section{References}

1. Sostegni R, Daperno M, Scaglione N, Lavagna A, Rocca R and Pera A: Review article: Crohn's disease: monitoring disease activity. Aliment Pharmacol Ther 17 (Suppl 2): 11-17, 2003.

2. Steinhart H: Maintenance therapy in Crohn's disease. Can J Gastroenterol 14 (Suppl C): 23c-28c, 2000.

3. De Cruz P, Kamm MA, Hamilton AL, Ritchie KJ, Krejany EO Gorelik A, Liew D, Prideaux L, Lawrance IC, Andrews JM, et al: Crohn's disease management after intestinal resection: A randomised trial. Lancet 385: 1406-1417, 2015.

4. Gyger $G$ and Baron M: Systemic sclerosis: Gastrointestinal disease and its management. Rheum Dis Clin North Am 41: 459-473, 2015.

5. Park JH, Nam HN, Lee JH, Hong J, Yi DY, Ryoo E, Jeon IS and Tchah $\mathrm{H}$ : Characteristics of upper gastrointestinal tract involvement in Korean pediatric Crohn's disease: A multicenter study. Pediatr Gastroenterol Hepatol Nutr 20: 227-235, 2017.

6. Roy A and Lichtiger S: Clostridium difficile infection: A rarity in patients receiving chronic antibiotic treatment for Crohn's disease. Inflamm Bowel Dis 22: 648-653, 2016.

7. Sofia MA, Lipowska AM, Perez EY, Zmeter N, Kavitt R and Rubin DT: Poor sleep quality in Crohn's disease is associated with antibiotic use and Gerd symptom severity. Gastroenterology 152: S799, 2017.

8. Valizadeh N, Murray AC, Suradkar K, Al-Mazrou A and Kiran RP: Impact of preoperative steroid or immunosuppressant use on short-term outcomes following colectomy in Crohn's disease patients. Tech Coloproctol 21: 217-223, 2017. 
9. Hazlewood GS, Rezaie A, Borman M, Panaccione R, Ghosh S, Seow CH, Kuenzig E, Tomlinson G, Siegel CA, Melmed GY, et al: Comparative effectiveness of immunosuppressants and biologics for inducing and maintaining remission in Crohn's disease: A network meta-analysis. Gastroenterology 148: 344-354, 2015

10. Fedorak RN, Feagan BG, Hotte N, Leddin D, Dieleman LA, Petrunia DM, Enns R, Bitton A, Chiba N, Paré P, et al: The probiotic VSL\#3 has anti-inflammatory effects and could reduce endoscopic recurrence after surgery for Crohn's disease. Clin Gastroenterol Hepatol 13: 928-935, 2015.

11. Lichtenstein L, Avni-Biron I and Ben-Bassat O: Probiotics and prebiotics in Crohn's disease therapies. Best Pract Res Clin Gastroenterol 30: 81-88, 2016.

12. Bouguen G, Levesque BG, Feagan BG, Kavanaugh A, PeyrinBiroulet L, Colombel JF, Hanauer SB and Sandborn WJ: Treat to target: A proposed new paradigm for the management of Crohn's disease. Clin Gastroenterol Hepatol 13: 1042-1050, 2015.

13. Biancone L, Tosti C, Fina D, Fantini M, De Nigris F, Geremia A and Pallone F: Review article: Maintenance treatment of Crohn's disease. Aliment Pharmacol Ther 17 (Suppl 2): 31-37, 2003.

14. Kroeker KI and Lu C: Probiotic Treatment in Crohn's Disease. In: Microbiota in Gastrointestinal Pathophysiology. Floch MH, Ringel Y and Walker WA (eds). 1st edition. Academic Press, Cambridge, MA, pp331-341, 2017.
15. Derwa Y, Gracie DJ, Hamlin PJ and Ford AC: P622 Efficacy of probiotics in inflammatory bowel disease: Systematic review and meta-analysis. J Crohn's Colitis 11 (Suppl 1): S398-S399, 2017.

16. Sands BE: Medical therapy of steroid-resistant Crohn's disease. Can J Gastroenterol 14 (Suppl C): 33c-37c, 2000.

17. Wood P, Henderson P and Wilson D: P516 Adrenal suppression in inflammatory bowel disease patients treated with glucocorticoids: A systematic review. J Crohn's Colitis 11 (Suppl 1): S342-S343, 2017.

18. Soriani P, Tontini GE, Neumann H, Ishaq S, Annunziata ML, Pastorelli L and Vecchi M: Esophageal post-inflammatory polyposis in extensive and severe Crohn's disease treated with anti-tumor necrosis factor alpha. Endoscopy 48 (Suppl 1): E261-E262, 2016.

19. Zhang J, Chen SL and Li LB: Correlation between intestinal flora and serum inflammatory factors in patients with Crohn's disease. Eur Rev Med Pharmacol Sci 21: 4913-4917, 2017.

(i) $(9)$ This work is licensed under a Creative Commons Attribution-NonCommercial-NoDerivatives 4.0 International (CC BY-NC-ND 4.0) License. 